\title{
Interrelation between frequency, dominance and dry-weight percentages of species in grassland vegetations
}

\author{
J. G. P. Dirven 1, B. J. Hoogers ${ }^{2}$ and D. M. de Vries ${ }^{2}$
}

1 Department of Field Crops and Grassland Husbandry, Agricultural University, Wageningen, the Netherlands

2 Institute for Biological and Chemical Research on Field Crops and Herbage, Wageningen, the Netherlands

Received 27 March 1969

\section{Summary}

In botanical grassland research in the Netherlands mainly the dry-weight analysis and the combined $25 \mathrm{~cm}^{2}$ frequency and order method have been applied. Since the botanical composition of many fields has been analysed by both methods, it was possible to study the interrelation between the percentages of frequency, dominance and dry weight.

The results show that the relation between dominance and percentage dry weight is dependent on the plant size/quadrat size ratio. As this quotient is greater, the relation will progressively approach the $45^{\circ}$-line. In the analysis of tropical grasslands it is possible to rapidly obtain sufficiently reliable information about the quantitative ratios of the various grass species by determining the dominance percentage.

The relation between frequency percentage $(\mathrm{F} \%)$ and dominance percentage (D \%) is also determined by plant size/quadrat size ratio and can be expressed by the general equation: $\mathrm{D} \%=-\mathrm{m}^{10} \log (100-\mathrm{F} \%)+2 \mathrm{~m}$. The coefficient, $\mathrm{m}$, is a reliable standard of the dominance tendency of the grassland species.

\section{Introduction}

The botanical composition of grassland can be analysed in several ways. In this country mainly the dry-weight analysis and the combined $25 \mathrm{~cm}^{2}$ frequency and order method have been applied in botanical grassland research (de Vries, 1949; de Vries and de Boer, 1959). In the first method the various grass species in a collective sample are separated, dried and weighed, after which the weight percentages of the species are calculated. This method is suitable for comparative botanical research of experimental fields.

Phytosociological and ecological research of the Dutch grasslands, however, has been done by the combined $25 \mathrm{~cm}^{2}$ frequency and order method. In this method the presence of a species in $25 \mathrm{~cm}^{2}$ borings or handfuls is noted, together with an assessment of which species ranks first, second or third in order of bulk. Based on these data frequency and dominance percentages can be calculated. Since many of these samples have also been examined by the dry-weight analysis, the interrelation between these percentages could be studied also. The question is whether the frequency and dominance percentages give sufficiently reliable information about the quantitative ratios of the species in the sward. 


\section{Relation between dominance and dry-weight percentage}

The percentage of dominance frequency (DF \%), briefly dominance percentage (D \%) - which is the number of times a species takes first place in bulk in 100 borings or handfuls - , in addition to its quantitative occurrence is dependent on the growth habit of the grass species and the quadrat size. These factors can therefore affect the relation between D \% and DW \% (percentage dry weight).

The influence of growth habit at the same quadrat size (here $25 \mathrm{~cm}^{2}$ ) on the relation is illustrated in Fig. 1, in which the percentages dry weight of Lolium perenne L.,
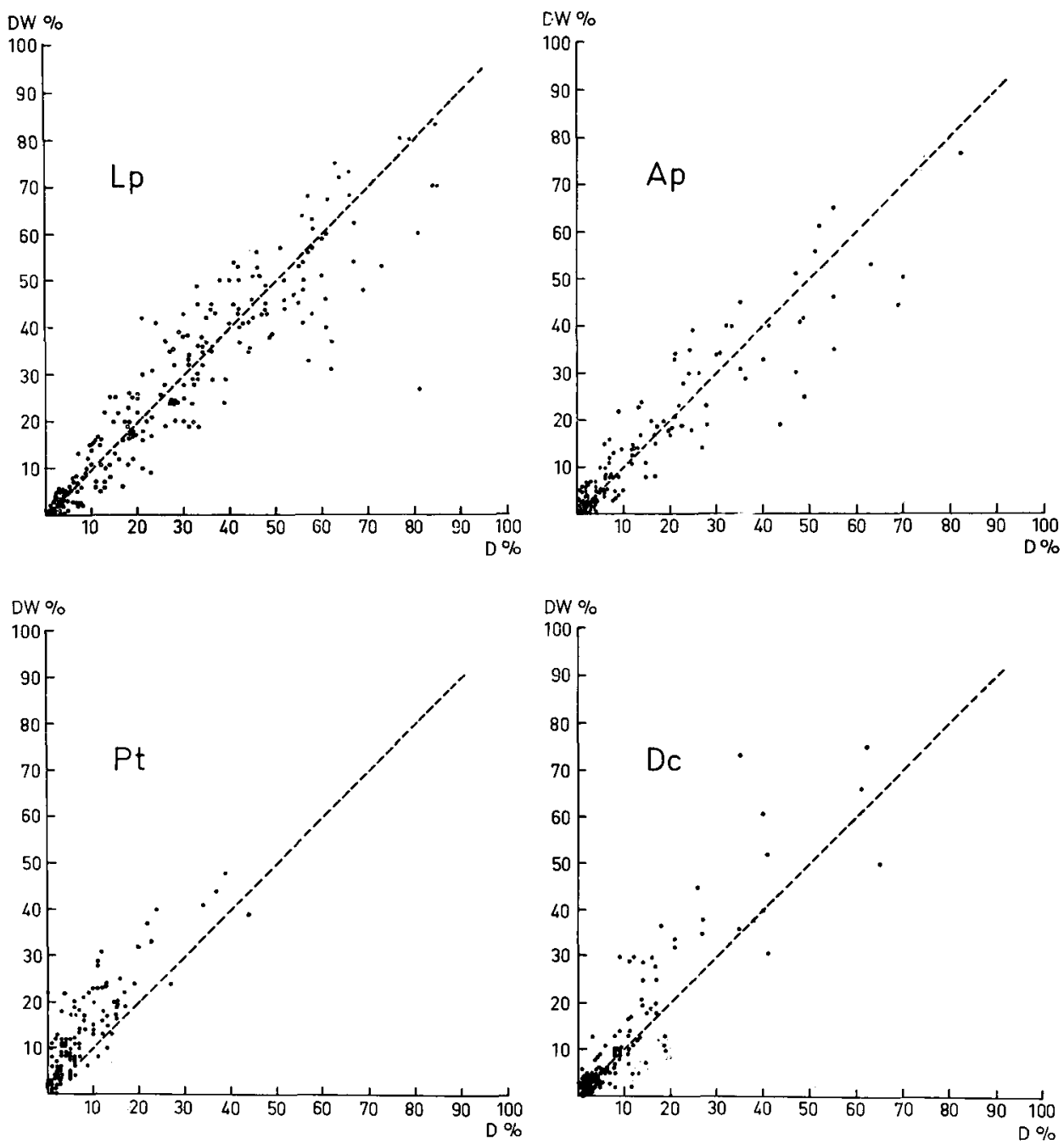

Fig. 1 Relation between dominance ( $D \%$ ) and dry-weight percentages ( $D W \%$ ) of Lolium perenne $(L p)$, Alopecurus pratensis $(A p)$, Poa trivialis $(P t)$ and Deschampsia cespitosa $(D c)$ in $25 \mathrm{~cm}^{2}$ readings 
Poa trivialis L., Alopecurus pratensis L., and Deschamps:a cespitosa P.B. have been plotted against corresponding $\mathrm{D} \%$. The $45^{\circ}$-line has also been drawn in this figure. The following selection was made from the data, regarding the type of use and time of sampling of the different grass species:

Lolium perenne $(\mathrm{Lp})$

Poa trivialis $(\mathrm{Pt})$

Alopecurus pratensis (Ap)

Deschampsia cespitosa (Dc)
Type of use

grazed only

grazed only

mown and grazed

mown and grazed
Time of sampling

autumn

spring

spring

all seasons

Fig. 1 shows a fair relation between DW \% and D \% of Lolium perenne and Alopecurus pratensis. However with more evenly distributed grass species, such as Poa trivialis, the DW \% - especially the lower values - are considerably higher than the corresponding D \%. Although the proportion by weight of this species may be fairly high, it will dominate less frequently in a $25 \mathrm{~cm}^{2}$ quadrat than the other species in equal proportion. The relation between DW \% and D \% in Deschampsia cespitosa is different from that in Lolium perenne. The difference is due mainly to the different growth habits of this species with different management. When used only for grazing this species may form large dense tufts, because cattle avoid it, whereas when cut also for hay it will be more evenly distributed. The higher values in the graph have been derived mostly from hayfields.

The dependence of the relation between DW $\%$ and D \% on the quadrat size can easily be explained. With increasing quadrat sizes the specific composition whithin the sampling unit will correspond more closely to that of the vegetation to be investigated. This implies that in a rather homogeneous grass sward the $\mathrm{D} \%$ of the most important species will rise to 100 fairly rapidly with increasing quadrat sizes. In a grass sward composed of many species this will proceed less rapidly. With a $\mathrm{D} \%$ of 100 the relevant weight percentage — depending on the quadrat size may vary considerably.

From the preceding it may be inferred that the relation between D\% and DW \% is determined by the plant size/quadrat size ratio. As this quotient is greater, the relation will progressively approach the $45^{\circ}$-line. This is shown in the relation between $\mathrm{D} \%$ and coverage (in a low growing sward almost identical with DW \%) in Fig. 2, which data refer to $1 \mathrm{dm}^{2}$ readings of Ischaemum timorense pastures in Surinam. The different species growing in these pastures are contagiously distributed within areas considerably larger than those of the quadrat used. Of course, the coverage is more reliably registered by using the point-quadrat method, but by increasing the quadrat size, information is also obtained about the density and distribution of the respective species. Moreover, the frequency and order method can be easily applied in the usually rather high tropical grass vegetation.

\section{Relation between frequency and dominance percentage}

The presence frequency percentage (PF \%), briefly frequency percentage $(\mathrm{F} \%)$, in a rather complex way expresses the quantitative importance of a grass species in the sward. This percentage is dependent on the quadrat size, density, size and distribution of the grass species. Proceeding from a random distribution of plants and qua- 


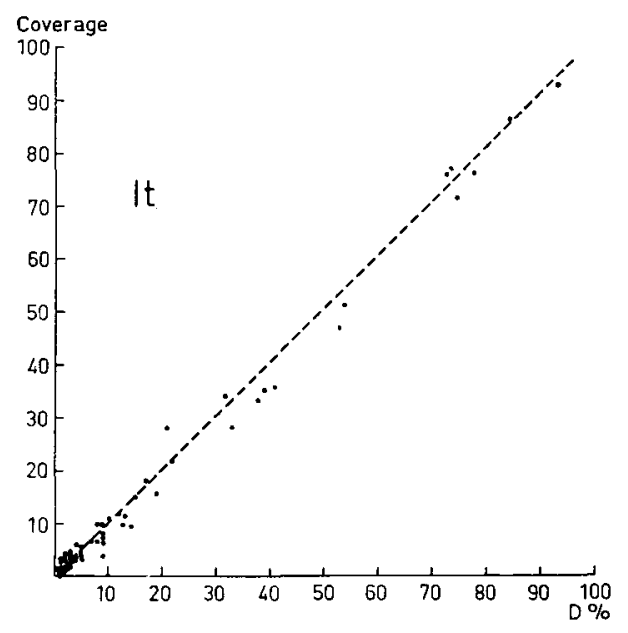

Fig. 2 Relation between dominance percentages $(D \%)$ and coverage of different grass species in $1 \mathrm{dm}^{2}$ readings of Ischaemum timorense (It) pastures

drats, Abardeen (1954) formed an equation, expressing the dependence of the frequency of the first three quantities:

$a-e^{-\pi(R+r)^{2} d}$

where $\mathrm{a}$ is the absence expressed in the value $0-1 ; \mathrm{R}$, the radius of a circular sampling unit; $r$, the radius of a circle covered by a plant unit; $d$, the density of the relevant plant unit.

With this equation the relation between $F \%$ and coverage at various quadrat and plant sizes has been plotted in Fig. 3, assuming that the plants do not overlap, so that the coverage may be put equal to $\pi \mathrm{r}^{2} \mathrm{~d}$. The figure shows that this relation is determined by the plant size/quadrat size ratio. If the quadrat size is infinitesimally small compared to that of the plant size - in case of the point-quadrat method -

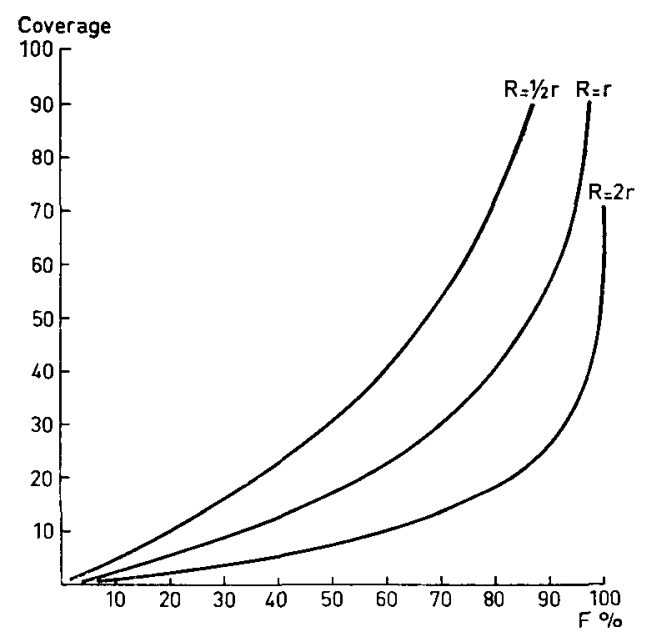

Fig. 3 Relation between frequency percentage $(F \%)$ and coverage at various quadrat $(R)$ and plant sizes $(r)$ 
the relation will be rectilinear and identical with the $45^{\circ}$-line. With increasing quadrat size the $F \%$ of the grass species with a low coverage will continue to rise and finally attain a value of 100 . As a result the curve will be progressively concave until it changes into line $\mathrm{x}=100$.

This relation was tested to the species for which other data were presented in Fig. 1. D \% and DW \% were available as a standard for abundancy. Since the weight analysis was usually carried out in a sub-sample, we preferred - also with a view to the reliability of the data - to plot the $\mathrm{D} \%$ against the $\mathrm{F} \%$. This relation has been presented in Fig. 4.
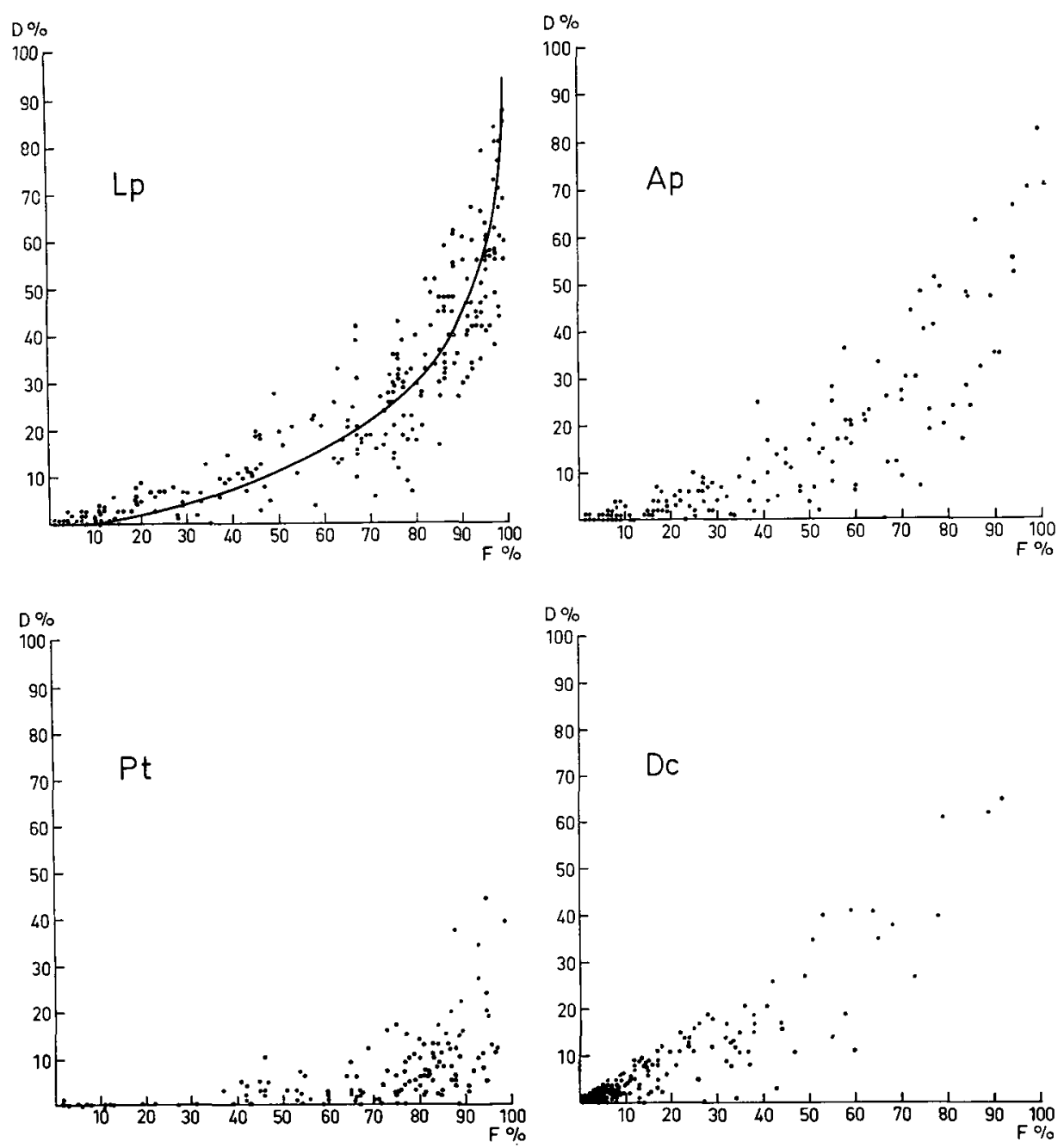

Fig. 4 Relation between frequency $(F \%)$ and dominance percentages $(D \%)$ of Lolium perenne $(L p)$, Alopecurus pratensis $(A p)$, Poa trivialis $(P t)$ and Deschampsia cespitosa $(D c)$ in $25 \mathrm{~cm}^{2}$ readings 
As has already been mentioned the quadrat size used in these investigations was $25 \mathrm{~cm}^{2}$. Dependent on the growth habit of the grass species - tufted or evenly distributed species - the curvilinear relation between F \% and D \% was found to be more concave in the order Deschampsia cespitosa, Lolium perenne, Alopecurus pratensis and Poa trivialis, which corresponds with the curves calculated in Fig. 3 . The points are rather scattered, due to the differences in botanical composition of the fields from which the data were derived. With the same F\% the D \% of Lolium perenne - dependent on the associate species (e.g. Agrostis stolonifera or Dactylis giomerata) - may differ appreciably. Aggregation of the relevant grass species, tiller weight, time and method of sampling (borings or handfuls) will also affect this scatter. The relation between these two quantities was calculated for Lolium perenne (Fig. 5). This was also done for the relation between $\mathrm{F} \%$ and $\mathrm{DW} \%$ of the same species and the following equations were formed:

$\mathrm{D} \%=-47 .{ }^{10} \log (100-\mathrm{F} \%)+92.0$

$\mathrm{DW} \%=-47.0^{10} \log (100-\mathrm{F} \%)+90.4$

The difference between these two equations proved to be small, which, based on the relation found between D \% and DW \% of this species (Fig. 1), was to be expected. Since the relation between $\log$ absence and $\mathrm{D} \%$ is rectilinear, the regression equations should only be calculated, if the F\% of the relevant grass species is between 90 and 99 in a good many samples. Several calculations have shown that the relation between $\mathrm{F} \%$ and $\mathrm{D} \%$ of the different grassland species can be reflected in the general equation:

$\mathrm{D} \%=-\mathrm{m}^{10} \log (100-\mathrm{F} \%)+2 \mathrm{~m}$

The coefficient $\mathrm{m}$ would appear therefore a more suitable standard for the dominance tendency of grassland species than the quotient $\frac{\mathrm{DF}}{\mathrm{PF}}$ multiplied by 100 , introduced by de Vries and Hoogers (1959). The influence of the type of use on the dominance

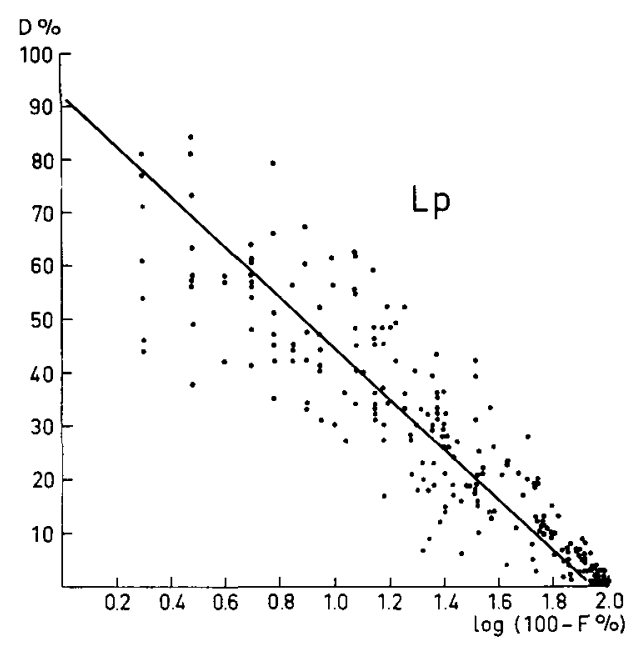

Fig. 5 Relation between log absence (100$F \%)$ and dominance percentage ( $D \%$ ) of Lo. lium perenne $(L p)$ in $25 \mathrm{~cm}^{2}$ readings 
tendency found by these authors should, in fact, be due to the varying level of the average $\mathrm{F} \%$ with differing types of use. Thus with higher $\mathrm{F} \%$ the quotient $\frac{\mathrm{DF}}{\mathrm{PF}}$ will increase, also depending on the plant size/quadrat size ratio.

\section{Acknowledgments}

The authors wish to thank Miss A. H. van Rossem for translating the manuscript.

\section{References}

Aberdeen, J. E. C., 1954. Estimation of basal or cover aress in plant ecology. Aust. J. Sci. 17: $35-36$.

Aberdeen, J. E. C., 1958. The effect of quadrat size, plant size and plant distribution on frequency estimates in plant ecology. Aust. J. Bot., 6: 47-58.

Vries, D. M. de, 1949. Survey of methods of botanical analysis of grassland. Rep. 5th Intern. Grassl. Congr. Neth.: 143-153.

Vries, D. M. de \& Th. A. de Boer, 1959. Methods used in botanical grassland research in the Netherlands and their application. Herb. Abstr. 29:1-7 (Review article).

Vries, D. M. de \& B. J. Hoogers, 1959. Distribution of tiliers of plant species in old permanent grassland with different types of use. Neth. J. agric. Sci. 7: 232-236.

\section{REVIEWS}

633.841:581.192:631.8(595)

P. W. F. de Waard : Foliar diagnosis, nutrition and yield stability of black pepper (Piper nigrum L.) in Sarawak. Thesis, Agricultural Univ. Wageningen, 1969. Communications of the Department of Agricultural Research No 58, Koninklijk Instituut voor de tropen, pp. 149.

Until 1942 cultivation of pepper $P$. nigrum L. in Sarawak produced relatively small but regular yields. High demands after 1945 and restricted use of 'burnt earth' compelled farmers to abandon the application of this traditional fertilizer. Instead, 'fool proof' manufactured fertilizers of mainly organic 